\section{Hydraulic Action}

\author{
Jeffrey R. Keaton \\ Amec Foster Wheeler, Los Angeles, CA, USA
}

\section{Definition}

Hydraulic action refers to the physical weathering and mechanical response of earth materials to flowing water in rivers and streams or breaking waves and storm surge along shorelines. Physical weathering by flowing water is a rockwater interaction phenomenon (Keaton, 2013). Hydraulic action implies that the water exhibits Newtonian behavior (velocity-dependent hydraulic shear strength) and has sediment concentration less than about $33 \%$ by mass corresponding to a fluid unit weight no greater than about $13 \mathrm{kN} / \mathrm{m}^{3}$. Such clear water could erode degradable rock by gradual and progressive abrasion and grain-scale wearing away and might erode jointed fragments of durable rock by quarrying and plucking depending on the size and shape of the rock fragments and turbulence intensity and velocity of the flowing water. Gradual and progressive wear of degradable rock persists in response to the stream power of the flowing water; degradable rock wears away faster in response to flow that has higher unit stream power. Quarrying and plucking of durable rock fragments is a threshold phenomenon that is indexed to the flow velocity; dislodgment of rock fragments tends to happen at flows that reach and exceed certain velocities.

Breaking waves and storm surge along shorelines have substantial energy and repeated application over a relatively small range of earth material extent. Degradable rock material tends to wear rapidly, leading to creation of ragged and rough coastal bluffs that continually slough earth material to the coastline below. The ability of the breaking waves and storm surge creates a slope profile that is limited by the rate of weathering and sloughing of material on the slope above sea level, because the shoreline processes have capacity to transport as much eroded rock and soil as the slope can produce. Durable rock material tends to erode slowly after the smaller fragments defined by closely spaced rock defects have been removed.

Erosion protection of river banks and beds, bridge piers and abutments, and shorelines from the hydraulic action of flowing water and waves and storm surge typically is provided by placement of armour stone or riprap.

Hydraulic action also can refer to the effect of hydrostatic pressure acting in all directions and its destabilizing action on soil and rock slopes.

\section{Cross-Reference}

$>$ Armour Stone

\section{References}

Keaton JR (2013) Estimating erodible rock durability and geotechnical parameters for scour analysis. Environ Eng Geosci XIX(4):319-343 